\title{
What Research Has to Say About Gender-Linked Differences in CMC and Does Elementary School Children's E-mail Use Fit This Picture?
}

\author{
Hans van der Meij
}

Published online: 28 July 2007

(C) Springer Science + Business Media, LLC 2007

\begin{abstract}
This paper first reviews the literature on computer mediated communication (CMC) to examine whether claims about gender-linked differences in specific attitudes, styles and content in CMC have been validated. Empirical studies were limited, with considerable variation in audiences, tasks, and contexts that was related to varied outcomes. The paper next describes an empirical study on the e-mail communication of elementary school children from ten Dutch classrooms. No gender-linked preference for a person or task-oriented attitude was found. Girls significantly more often employed an elaborate style. Differences between boys and girls on content of communication were subtle rather than robust. The conclusion discusses the functional embedding of CMC and the need to examine jointly antecedents, language acts and consequences.
\end{abstract}

Keywords Gender CMC · Markers · Communication styles

\section{Introduction}

Research on computer mediated communication (CMC) has examined the claim that it affords more egalitarian participation for men and women. As a lean medium, CMC would be more democratic because it reduces gender-linked power differences through its open access and the possibilities for communicative partners to remain anonymous (e.g., Danet 1998; Jessup et al. 1990). Numerous studies have found otherwise. Unless special measures are taken to

H. van der Meij $(\bowtie)$

Department of Instructional Technology,

Faculty of Behavioral Science, University of Twente,

P.O. Box 217, 7500 AE Enschede, The Netherlands

e-mail: meij@edte.utwente.nl improve conditions for participation, men dominate in $\mathrm{CMC}$ in much the same way as they do in other communication contexts (e.g., Herring 1996; Lee 2003; Prinsen et al. 2007a; Postmes et al. 2000). Yates (2001) succinctly summarizes the findings by stating that "many writers who hoped to see $\mathrm{CMC}$ remove inequalities have ignored the fact that social structures and social practices...are in most cases constructed and enacted through communication" (p. 27). Under favorable participation conditions gender-linked differences may emerge in CMC because of the nature of the medium. That is, the virtual absence of possibilities of communicating non-verbally stimulates partners to express themselves in relatively elaborate ways (e.g., Epley and Kruger 2005; Palomares 2004).

The first part of this paper scrutinizes the literature on gender-linked differences in CMC. This review serves two purposes. One, it examines the empirical evidence for claims about specific gender-linked attitudes, styles and content in CMC. We look at research on a task or person-oriented attitude towards CMC, usage of a succinct or elaborate style and presence of task or person-oriented content in CMC. We shall illustrate that there is considerable variation in how these variables are measured, in audiences, tasks, and contexts, and in reported findings. The review further reveals that research with elementary school children is scarce. This limits the second purpose of the review to that of a general framework for the empirical study on gender-linked differences in CMC use by elementary school children that is reported in the second part of this paper. The review suggests how dependent variables should be measured, offers tentative predictions and further draws attention to important conditions, antecedents and consequences. The description of individual studies in the review will be selective and concentrate on research that is in some way related to the ensuing empirical study. 
Gender and Attitude towards Communication in CMC

An important stereotype is that men are more task-oriented and women more person-oriented (e.g., Herring 1996; Lindsey and Zakahi 1998; Mulac et al. 2001a, b; Savicki et al. 1996; Tannen 1994). Men's communication often concentrates on activities. This 'report' approach supposedly originates from a strong task or information orientation and a tendency to communicate to establish and maintain independence and status. In contrast, the communication of women is often characterized as a 'rapport' approach. Females are seen as more strongly oriented toward people. Their communications indicate attitudes and behaviors associated with sharing in personal relationships.

Numerous case studies indicate that the attitude of men towards CMC is predominantly task-oriented and that of women person-oriented. The question therefore seems to be not whether this difference exists for $\mathrm{CMC}$, but rather whether its presence is more than a chance occurrence, and whether there are specific conditions in which this gender difference is most likely to appear. To answer these questions we carefully examined the vast literature on gender and CMC. The result is presented in Table 1. Inclusion in the list was based on three criteria. First, studies had to measure attitudes of people directly rather than by inferring these from, say, language acts. Second, studies had to measure a person or task-orientation in contrast to the more common measures of CMC anxiety, confidence, liking and usefulness. Third, studies had to test statistically for gender differences. From the hundreds of studies that we examined (including the 580 references in Sanders 2005) only six remained that satisfied these criteria. Table 1 summarizes the findings.
Colley's (2003) study reports on what children aged 1112 and 15-16 liked and disliked about school computing. Girls in both age groups gave higher ratings for the use of computers for information purposes. That is, elementary school girls, more so than boys, positively rated computer use for 'advantages for work' which stood for: helps presentation, checks spelling and grammar, makes work easy and so on. Secondary school girls also expressed a higher preference of computers for information purposes. In this case, they said they liked computers for 'learning' indicating that computers: help learning in general, provide useful sources of information, allow learning of new skills and the like. Colley concludes that the girls' attitude towards computers reflects their more serious approach to schoolwork. Colley's study examined the functionality of a varied set of applications. CMC (in the form of e-mail) was included, but so was use of the web for information-seeking. This complicates the interpretation of her findings because gender-linked attitudes can co-vary with applications (e.g., Oosterwegel et al. 2004).

A significantly higher female disposition towards $\mathrm{CMC}$ for task orientation is also reported by Price (2006) who found this preference for 'learning from other students' in a study on students' attitudes towards online courses. Odell et al. (2000), who asked students from different universities why they used the Internet, found that females indicated a stronger preference than men for using the Internet for "research for school," a type of task-oriented purpose. However, given the broad classification of type(s) of applications examined, it is not clear whether the findings relate solely to the Internet as an information source, or to the Internet as a means for interactive communication as well. The same restriction applies to the finding of Madell and

Table 1 Summary of empirical studies that have tested gender-linked differences in CMC attitudes for task or person-orientation.

\begin{tabular}{|c|c|c|c|c|}
\hline Number & Author(s) & Audience and task & Type of CMC & Task-person \\
\hline 1 & Allen (1995) & $\begin{array}{l}\text { Employees from an American organization gave } \\
\text { their views on e-mail use }\end{array}$ & E-mail & $\begin{array}{l}\text { ns: Person } \\
\text { F: Information }\end{array}$ \\
\hline 2 & Boneva et al. (2001) & $\begin{array}{l}\text { American adults gave opinions about communications } \\
\text { with family and friends }\end{array}$ & E-mail (predominantly) & $\begin{array}{l}\text { ns: Information } \\
\text { F: Person }\end{array}$ \\
\hline 3 & Colley (2003) & $\begin{array}{l}\text { English elementary and secondary school children } \\
\text { expressed views about likes and dislikes in school } \\
\text { computing }\end{array}$ & ICT use (including e-mail) & F: Information \\
\hline 4 & $\begin{array}{l}\text { Madell and Muncer } \\
\text { (2004) }\end{array}$ & $\begin{array}{l}\text { English secondary school students indicated why } \\
\text { they use Internet }\end{array}$ & Internet & F: Information \\
\hline 5 & Odell et al. (2000) & $\begin{array}{l}\text { American college students indicated their preferences } \\
\text { for types of Internet use in a survey }\end{array}$ & Internet & F: Information \\
\hline 6 & Price (2006) & $\begin{array}{l}\text { English university students gave opinions about an } \\
\text { online course from Open University }\end{array}$ & E-mail and computer conferencing & F: Information \\
\hline
\end{tabular}

All tested outcomes are presented, the statistically significant findings as well as the non-significant ones.

$F$ A statistically significant preference for females, $M$ a statistically significant preference for males, $n s$ not significant. 
Muncer (2004) who also report a female preference for Internet use for the purpose of "finding information related to education."

In conclusion, just a few studies have actually statistically tested whether men and women hold a different task or person-oriented attitude toward CMC. The majority of studies contradict the stereotypical view. All four studies in educational settings report a female preference for taskoriented uses of CMC. This outcome fits within a general view in which the appearance of working diligently in school is considered 'feminine' (e.g., Arnot 2006; Frank et al. 2003; Jackson 2002; Reay 2001; Younger et al. 2005). Boys often seek other ways of 'doing gender' in school. Research on Dutch elementary and secondary schools is consistent with this general view (Dolle-Willemsen 1997). Unfortunately, it is not certain whether the findings from the reviewed studies are representative for CMC because a varied set of applications were examined.

\section{Gender and Style of Communication in CMC}

The communication of men and woman can differ in many ways. Accordingly, one finds many reports that examine gender-linked differences for a wide variety of individual language features. These features are sometimes grouped together to signal the presence of a particular style of communication. Gender-linked differences are then examined on style dimensions. An important benefit of analyzing styles is that they yield an overall picture of language use that does not hinge on the presence of a single indicator. In this paper we concentrate on gender-linked differences for the style dimension of succinct-elaborate (see Mulac 1998).

We searched for and closely examined the literature on $\mathrm{CMC}$ that tested gender differences on this style dimension. The list of studies (see Table 2) is longer than for attitude, but it is still not extensive. The list includes studies with various dependent variables as signals for this style. We have excluded studies that reported only on 'number of messages' because this variable is likely to be confounded with a gender-linked difference in access to CMC.

\section{Succinct-Elaborate Dimension}

The talk of men tends to be characterized as terse, unembellished. It is sometimes referred to as 'plain talk' and qualified as a succinct style. The style of women tends to be seen as more expressive. With its more complex linguistic forms, more flowery and sometimes evasive expressions, it is characterized as elaborate (Mulac et al. 2001a). The most prominent language feature for this style dimension is text length. The reviewed studies use various indices to measure quantity of talk. In addition, we consider the presence of a gender-linked difference for markers.

Six studies report that women give more elaborate messages than men (numbers 2, 4, 9, 10, 13, 14 in Table 2). Text length measures and types of CMC vary in these studies. Females have been found to hold longer conversations in Instant Messenger (Baron 2004), to write texts with a longer mean sentence length in groupware (Mulac et al. 2001b), and to send out e-mails with more words (Colley et al. 2004; Savicki et al. 1996). Two studies report the presence of longer texts by girls from elementary school. In Li's 2002 study the clause was used as a measure of text length. Prinsen et al. (2007b), who examined Dutch elementary school children, measured the number of words. In both studies the children worked with Knowledge Forum.

The explanations for this finding vary by study. Baron (2004), who also reports other language features that indicate that females are more "talkative," suggests that the difference is one of female writing style, together with a more social orientation and a stronger adherence to normative language. Savicki et al. (1996) ascribe the outcome to a favorable context because an effect of gender appeared solely for female only groups. They suggest that female groups, as opposed to mixed-gender or male only groups, display a greater sensitivity to group processes which stimulate participation. Li (2002) does not speculate on the origins of the gender difference but simply concludes that "no definite conclusions can be drawn from this study" (p. 356). The research of Prinsen et al. (2007b) stands apart from the others by the fact that several input variables were measured before the start of the study. Statistical analyses revealed that there were significant effects on text length for 'reading comprehension' and 'popularity among class members,' as well as an interaction effect for gender and computer skills.

Several studies report the absence of a significant difference between men and women on text length (numbers 1, 2, 3, 5, 8, 11, 12, 16, 17 in Table 2). A majority of these studies involved college students using e-mail. Various arguments are advanced to account for the absence of a gender difference. For example, Adrianson (2001) 'blames' the equalization phenomenon, which essentially entails the argument that $\mathrm{CMC}$ affords a more level playing field for participants. Palomares (2004) argues that the scripted, unidimensional task, in combination with having an unspecified response partner, may have made the language context inconspicuous. According to self-categorization theory, to which he refers, this stimulates people to act in more neutral ways.

Only Sussman and Tyson (2000) found longer texts (i.e., longer posts to newsgroups) for men. They suggest that this primarily signals a power difference, with men contributing more because they are the dominant social group. As indicated earlier, this power argument frequently emerges in 
Table 2 Summary of empirical studies on CMC that have tested gender-linked preferences for style features in the dimension 'succinctelaborate' and for content in 'task or person-orientation.

\begin{tabular}{|c|c|c|c|c|c|}
\hline Number & Author(s) & Audience and task & Type of CMC & $\begin{array}{l}\text { Succinct- } \\
\text { elaborate style }\end{array}$ & $\begin{array}{l}\text { Task-person } \\
\text { content }\end{array}$ \\
\hline 1 & Adrianson (2001) & $\begin{array}{l}\text { Swedish university students working in } \\
\text { groups on two problem solving tasks }\end{array}$ & $\begin{array}{l}\text { E-mail } \\
\text { Asynchronous } \\
\text { One-to-one }\end{array}$ & $\begin{array}{l}\text { ns: Number } \\
\text { of words }\end{array}$ & \\
\hline 2 & Baron (2004) & $\begin{array}{l}\text { American college students holding } \\
\text { conversations }\end{array}$ & $\begin{array}{l}\text { Instant } \\
\text { messenger } \\
\text { Synchronous } \\
\text { One-to-one }\end{array}$ & $\begin{array}{l}\text { ns: Number } \\
\text { of words } \\
\text { F: Longest turns } \\
\text { F: Emoticons }\end{array}$ & \\
\hline \multirow[t]{2}{*}{3} & $\begin{array}{l}\text { Colley and Todd } \\
\text { (2002) }\end{array}$ & $\begin{array}{l}\text { English adults writing to a friend about } \\
\text { a holiday destination }\end{array}$ & E-mail & $\begin{array}{l}\text { ns: Number } \\
\text { of words }\end{array}$ & $\begin{array}{l}\text { F: Initial personal } \\
\text { inquiry }\end{array}$ \\
\hline & & & $\begin{array}{l}\text { Asynchronous } \\
\text { One-to-one }\end{array}$ & F: Strengtheners & $\begin{array}{l}\text { ns: Refs to } \\
\text { recipients' tastes } \\
\text { or attributes (but } \\
\text { F for } \mathrm{F}-\mathrm{M} \text { ) }\end{array}$ \\
\hline \multirow[t]{2}{*}{4} & $\begin{array}{l}\text { Colley et al. } \\
\text { (2004) }\end{array}$ & $\begin{array}{l}\text { English adults writing to a friend about } \\
\text { summer events }\end{array}$ & E-mail & $\begin{array}{l}\text { F: Number } \\
\text { of words }\end{array}$ & F: Family \\
\hline & & & $\begin{array}{l}\text { Asynchronous } \\
\text { One-to-one }\end{array}$ & F: Strengtheners & $\begin{array}{l}\text { F: Initial personal } \\
\text { inquiry }\end{array}$ \\
\hline 5 & $\begin{array}{l}\text { Guiller and } \\
\text { Durndell (2007) }\end{array}$ & $\begin{array}{l}\text { English college students engaging in } \\
\text { online discussions on course topics }\end{array}$ & $\begin{array}{l}\text { Forum } \\
\text { Asynchronous } \\
\text { One-to-many }\end{array}$ & $\begin{array}{l}\text { ns: Number } \\
\text { of words }\end{array}$ & F: Person-oriented \\
\hline 6 & $\begin{array}{l}\text { Huffaker and } \\
\text { Calvert (2005) }\end{array}$ & $\begin{array}{l}\text { Teenagers }(13-17) \text { posting personal } \\
\text { weblogs }\end{array}$ & $\begin{array}{l}\text { Weblogs } \\
\text { Asynchronous } \\
\text { One-to-many }\end{array}$ & ns: Emoticons & \\
\hline 7 & Jaffe et al. (1999) & $\begin{array}{l}\text { American college students participating } \\
\text { in a computer conference on a social } \\
\text { science course }\end{array}$ & $\begin{array}{l}\text { Forum } \\
\text { Synchronous } \\
\text { One-to-many }\end{array}$ & ns: Emoticons & \\
\hline 8 & Koch et al. (2005) & $\begin{array}{l}\text { German college students engaged in } \\
\text { a chat on a gender-neutral topic }\end{array}$ & $\begin{array}{l}\text { Chat } \\
\text { Synchronous } \\
\text { One-to-many }\end{array}$ & $\begin{array}{l}\text { ns: Number } \\
\text { of words }\end{array}$ & ns: Task-oriented \\
\hline 9 & Li (2002) & $\begin{array}{l}\text { Canadian elementary school children } \\
\text { communicated on math and science }\end{array}$ & $\begin{array}{l}\text { Knowledge } \\
\text { forum } \\
\text { Asynchronous } \\
\text { One-to-many }\end{array}$ & $\begin{array}{l}\text { F: Number } \\
\text { of clauses }\end{array}$ & \\
\hline 10 & $\begin{array}{l}\text { Mulac et al. } \\
\text { (2001b) }\end{array}$ & $\begin{array}{l}\text { American college students working } \\
\text { together on course tasks }\end{array}$ & $\begin{array}{l}\text { Groupware } \\
\text { Asynchronous } \\
\text { One-to-many }\end{array}$ & F: Sentence length & \\
\hline 11 & $\begin{array}{l}\text { O’Neill and Colley } \\
\text { (2006) }\end{array}$ & $\begin{array}{l}\text { English college students argued why } \\
\text { they failed to submit work to } \\
\text { administrator or professor }\end{array}$ & $\begin{array}{l}\text { E-mail } \\
\text { Asynchronous } \\
\text { One-to-one }\end{array}$ & $\begin{array}{l}\text { ns: Number } \\
\text { of words }\end{array}$ & F: Task-oriented \\
\hline 12 & Palomares (2004) & $\begin{array}{l}\text { American college students wrote to an } \\
\text { unknown recipient on 'What will society } \\
\text { be in } 2012 \text { ' }\end{array}$ & $\begin{array}{l}\text { E-mail } \\
\text { Asynchronous } \\
\text { One-to-one }\end{array}$ & ns: Sentence length & \\
\hline 13 & $\begin{array}{l}\text { Prinsen et al. } \\
\text { (2007b) }\end{array}$ & $\begin{array}{l}\text { Dutch elementary school children } \\
\text { communicated on science }\end{array}$ & $\begin{array}{l}\text { Knowledge } \\
\text { forum } \\
\text { Asynchronous } \\
\text { One-to-many }\end{array}$ & $\begin{array}{l}\text { F: Number } \\
\text { of words }\end{array}$ & \\
\hline 14 & $\begin{array}{l}\text { Savicki et al. } \\
\text { (1996) }\end{array}$ & $\begin{array}{l}\text { American college students exchanging } \\
\text { views about a decision-making task }\end{array}$ & $\begin{array}{l}\text { E-mail } \\
\text { Asynchronous } \\
\text { One-to-one }\end{array}$ & $\begin{array}{l}\text { F: Number } \\
\text { of words }\end{array}$ & \\
\hline 15 & $\begin{array}{l}\text { Sussman and Tyson } \\
\text { (2000) }\end{array}$ & Individuals engaging in public discussion & $\begin{array}{l}\text { Newsgroups } \\
\text { Asynchronous } \\
\text { One-to-many }\end{array}$ & $\begin{array}{c}\text { M: Number } \\
\text { of words }\end{array}$ & \\
\hline 16 & $\begin{array}{l}\text { Thomson and } \\
\text { Murachver (2001) }\end{array}$ & $\begin{array}{l}\text { College students from New Zealand } \\
\text { exchanging messages with a netpal }\end{array}$ & E-mail & $\begin{array}{l}\text { ns: Number } \\
\text { of statements }\end{array}$ & $\begin{array}{l}\text { F: Personal } \\
\text { information }\end{array}$ \\
\hline
\end{tabular}


Table 2 (continued)

\begin{tabular}{|c|c|c|c|c|c|}
\hline Number & Author(s) & Audience and task & Type of CMC & $\begin{array}{l}\text { Succinct- } \\
\text { elaborate style }\end{array}$ & $\begin{array}{l}\text { Task-person } \\
\text { content }\end{array}$ \\
\hline & & & $\begin{array}{l}\text { Asynchronous } \\
\text { One-to-one }\end{array}$ & ns: Message length & \\
\hline 17 & $\begin{array}{l}\text { Thomson et al. } \\
\text { (2001) }\end{array}$ & $\begin{array}{l}\text { College students from New Zealand } \\
\text { exchanging messages with two netpals }\end{array}$ & $\begin{array}{l}\text { E-mail } \\
\text { Asynchronous } \\
\text { One-to-one }\end{array}$ & $\begin{array}{l}\text { ns: Number } \\
\text { of words }\end{array}$ & $\begin{array}{l}\text { ns: Personal } \\
\text { information }\end{array}$ \\
\hline 18 & $\begin{array}{l}\text { Witmer and } \\
\text { Katzman (1997) }\end{array}$ & $\begin{array}{l}\text { Individuals who posted messages on } \\
\text { newsgroups and special interest groups }\end{array}$ & $\begin{array}{l}\text { Newsgroups } \\
\text { Asynchronous } \\
\text { One-to-many }\end{array}$ & F: Emoticons & \\
\hline 19 & Wolf (2000) & $\begin{array}{l}\text { Individual posts on newsgroups about female, } \\
\text { male and mixed topics }\end{array}$ & $\begin{array}{l}\text { Newsgroups } \\
\text { Asynchronous } \\
\text { One-to-many }\end{array}$ & $\begin{array}{l}\text { ns: Emoticons and } \\
\text { Strengtheners }\end{array}$ & \\
\hline
\end{tabular}

For 'text length' we report the following dependent measures: message length, sentence length, number of statements, longest turn, clauses and number of words. All tested outcomes are presented, the statistically significant findings as well as the non-significant ones.

$F$ A statistically significant preference for females, $M$ a statistically significant preference for males, $n s$ not significant.

discussions on CMC when access and conditions for participation are at stake.

Another important language feature in the succinctelaborate style dimension is the marker. A marker emphasizes text segments by visual means. As a nonverbal sign of expressiveness it nicely complements the verbal feature of text length. According to Crystal (2001) markers can reduce ambiguity and distortions in communication, serving the same role as variations in pitch, loudness, tone of voice and stress do in face-to-face communication (see also social information processing (SIP) theory, Walther et al. 2005b). The most famous marker is the emoticon or smiley. But $\mathrm{CMC}$ can also contain markers in the form of an excessive use of capitals, intentional misspellings (e.g., soooo good), and multiple exclamation marks. These types of markers are called strengtheners henceforth.

Seven empirical studies have tested the presence of a gender-linked preference for markers (numbers 2, 3, 4, 6, 7, 18, 19 in Table 2). Four studies report a female preference and three studies report non-significant outcomes. Both studies by Colley and colleagues found a significant female preference for the use of markers in the form of multiple signs of exclamation and excitability (capitalization) in e-mails. This is explained by referring to females' greater sensitivity to communal and socio-emotional aspects of communication. Baron (2004) and Witmer and Katzman (1997) found more emoticons in women's messages in respectively Instant Messenger, and newsgroups and special interest groups. Baron again points to a difference in female writing style along with a more social orientation and a stronger adherence to language standards. Witmer and Katzman suggest that the finding signals more female social warmth, as well as stronger sensitivity to aesthetic qualities and emotional expressiveness.
Both studies report a relatively low incidence of emoticons (also see Guiller and Durndell 2007; Savicki et al. 1996).

Huffaker and Calvert (2005), in contrast, report a high usage of emoticons. $63 \%$ of the teenagers in their study presented an emoticon at least once in their weblogs. No gender difference was found. Wolf (2000) too mentions the presence of a considerable number of emoticons (i.e., $38 \%$ of all posts) in mixed-gender newsgroups. She suggests that there was no gender difference because the men aligned to the style used by the females in these groups. Jaffe et al. (1999) also found no gender difference for 'emotional texts,' a mixture of emoticons and strengtheners, in the communication of college students. The absence was accounted for by stating that both male and female alike had 'a need for evocative expression' (p. 230).

In conclusion, women appear to use a more elaborate style in CMC. Six out of seven studies that report significant findings for text length indicate that women write longer messages. Among these are the two studies involving elementary school children. Baron's (2004) explanations for the finding are especially interesting when seen against the backdrop of commonly reported higher language achievements of girls in elementary and secondary school in western societies (e.g., Mullis et al. 2001; Van Langen and Driessen 2006). The relationship that Prinsen et al. (2007b) report between reading comprehension and text length further supports the view that language skills, along with other factors, are influential. For markers, a small majority of studies report a more heavy use of this feature by women. Explanations of why females express themselves more often in this way are that markers afford a stronger display of social warmth and that they better harmonize with soughtafter aesthetic qualities and emotional expressiveness. 


\section{Gender and Content of Communication in $\mathrm{CMC}$}

Just as for attitude, we concentrate in the content analyses on task or person-oriented communications. We closely examined the literature and found only a few empirical studies that tested the existence of a gender-linked difference in the specified content in CMC.

Supportive evidence for a female preference for personoriented communication is reported in four studies (numbers 3, 4, 5, 16 in Table 2). Guiller and Durndell (2007) found that female students in online discussion groups more often engaged in self-disclosure, which stood for 'sharing of personal information beyond that of opinion, experience and emotion.' In the other three studies, the communications took place in conditions that were already heavily person-oriented by design (e.g., write to a friend about a summer event).

Both Koch et al. (2005) and Thomson et al. (2001) report an absence of gender-linked differences for task or person-orientedness. The experiments reported in Thomson et al. are special in that they assume, on the one hand, that there is such a thing as a gender-linked preference for topic of communication, and, on the other hand, that this can be strongly affected by alignment. The studies depart from the notion that women's talk is more person-oriented. The idea tested is that participants are strongly affected by their partner's (a confederate acting as male or female) communication. They were expected to align rather than hold onto their own preference. The prediction was confirmed in the two reported studies. Communication was strongly affected by the partner. Both male and female students more often exchanged personal information with a female partner than with a male partner.

The study by O'Neill and Colley (2006) stands apart with its finding of a female dominance in task-oriented communication. Female students mentioned work-related issues more often in their e-mails than men. A unique feature of this study is that participants held an asymmetric relationship with their partner (i.e., students communicated with a teacher or supervisor).

In short, the results seem to confirm the stereotype. Four studies indicate that the communication of men better fits a 'report' approach by concentrating on task-oriented information. The communication of women contains more personoriented matter and is in line with a 'rapport' approach. It is noteworthy that this finding stands in direct contrast to the outcome for attitude. It must be kept in mind that nonsignificant and contrasting outcomes were also reported, and that context may have played an important role.

\section{Concluding Remarks About the Literature Review}

Relatively few empirical studies have tested gender-linked differences for the attitudes, styles and content in CMC examined in this review. From the hundreds of studies that we explored, only a handful remained after selection. Are such empirical studies scarce because we looked at CMC, or is this more generally the case for the examined variables? We have no direct answer to this question, but merely report that we found no reviews that set out to validate gender-linked claims for a task or person-oriented attitude or content. For style we found a single, non-CMC study. Mulac (1998) has reviewed the literature for genderlinked difference on the succinct-elaborate style dimension, and found a female preference.

The following tentative predictions can be formulated on the basis of the presented literature review: females have a stronger task-oriented attitude and use a more elaborate style; males have a higher proportion of task-oriented content in their communications. The empirical study reported next examines whether these gender-linked differences for attitude, style and content emerge for e-mail use in Dutch elementary schools.

The review indicates that variations in audiences, tasks and contexts can all affect the outcomes. This raises the question of whether we can expect to find gender-linked differences in line with the predictions, given that we are studying Dutch children in elementary school. There is 'circumstantial evidence' and a pertinent research finding that indicate that the predictions may hold. First, studies on effects of gender on general computer attitudes of Dutch elementary school children yield findings that are consistent with findings reported for elementary school children in, for example, America and the UK (Meelissen and Drent 2007; Prinsen et al. 2007b). Second, large scale comparative studies such as PIRLS and PRIMA, indicate that the language skills of Dutch girls from elementary school are superior to those of Dutch boys, just as in many other western countries (Mullis et al. 2001; Van Langen and Driessen 2006). Third, observational studies indicate that the behaviors of boys and girls (and their teachers) in Dutch elementary schools are comparable to what is reported for other European countries and for the United States (Dolle-Willemsen 1997). Fourth, a recent study on Dutch elementary school children (Prinsen et al. 2007b) found that girls produced significantly longer texts (i.e., more words) in $\mathrm{CMC}$, which was related to gender-linked differences in language skills, in agreement with other reported findings from the review.

Still, the literature review cautions against making too broad claims about gender-linked differences. It signals that language use serves a purpose in a circumstance and that it is desirable to outline the circumstances of a study rather precisely. In the set-up of the empirical study, we therefore paid special attention to several key aspects of context. The introduction discusses how we tried to realize a functional embedding of e-mail use in school. The method section describes the actual use of e-mail in the study on dimensions of synchronicity and grouping. We indicate there that 
the same-sex grouping in the study is likely to strengthen existing gender-linked tendencies and argue that there is a within-group focus that reduces the risk that outcomes are confounded due to an alignment with the partner.

Introduction to the Empirical Study on Email Use in Elementary School

The rapid expansion of electronic tools confronts many educators in Western societies with the challenge of selecting those that can be meaningfully employed in school. In this study we focus on e-mail. In contrast to its widespread adoption in business and at home, e-mail use in school has been slow to catch on. Existing studies concentrate on second-language learning and its corollary of intercultural understanding (e.g., Itakura 2004; Liaw and Johnson 2001; Vinagre 2005).

O'Dowd (2003) presents an illuminating study on these issues. After criticizing earlier studies as lacking integration, the author took three main measures to embed e-mail usage into classroom practices. First, the main goals for intercultural exchange were set to provide a clear focus for the lessons. Next, the lessons confronted students with a series of critical tasks to ensure that they would deal with these goals. For example, to cue students to the link between language and culture, they wrote down their associations for key words such as 'good food' and 'bullfighting' and exchanged these with their (Spanish or English) partner. Third, the teacher frequently gave feedback on the students' messages. This could be help on request, but the teacher would also take the initiative when action was called for. The author then describes the exchanges and argues why some partnerships succeeded and others failed in their communication and learning.

In the present study, e-mail was used as a means to stimulate elementary school children to look back on their classroom experiences and to share these reflections with other children. Apart from our own earlier studies (De Vries 2004; Van der Meij et al. 2005), no other research has examined this type of e-mail use. Just as in the research of O'Dowd (2003), we made a special effort to integrate e-mail use functionally in classroom practices. We did so by engaging all participants in a design project that lasted for two to three months. During this period a series of lessons were conducted in all classrooms on the topic of 'creating a device that can clean a pond.' All children in the classrooms worked in groups on their designs and communicated about their experiences with another group from another participating school.

Instead of O'Dowd's (2003) assigned tasks for communication, the project merely offered a shared framework or context for the exchanges. Children could freely select their own styles of and topics for discussion. Furthermore, whereas the teacher in O'Dowd's study played an active role in commenting on the e-mails, the teachers here were more or less passive, with infrequent and minimal feedback. Teachers tended to concentrate their comments on the first message and then mainly reminded students of general guidelines for e-mail contacts ('netiquette'). Norms of participation in the e-mail exchanges were therefore relaxed and open (compare Baron 2002; Herring 1996).

\section{Method}

Participants, Partnerships and Language Context

\section{Participants}

Ten fifth and sixth grade classrooms in the Netherlands volunteered to participate in the study. Their primary reason for participation was an interest in e-mail use in school. Like the large majority of Dutch classrooms at that time, they had little or no experience in that area. Classrooms came from public schools with different denominations. As far as we could establish, there was nothing unusual about their student populations or didactic approaches. Most of the children (mean age of 11.5 years) had some computer experience and could work with Word, but only a handful had any prior experience with e-mail. The children's experience with other forms of CMC was also virtually absent. Teachers generally introduced e-mail to the class as a whole and then gave the children some time to practice on the computer. A manual for teachers and children supported these activities.

\section{Partnerships}

During the project the children worked in groups most of the time. There were 82 groups. Teachers decided how the children could form groups. Groups always communicated with groups from another school. This paper concentrates on the communication of the all-boy and all-girl groups (henceforth simply referred to as boys or girls). That is, the data are reported from 16 groups of boys $(n=50)$ and 20 groups of girls $(n=60)$. Minimum group size was two; the maximum was four. Mean group size was almost identical for boys and girls $\left(\mathrm{Mean}_{\text {boys }}=3.13, \mathrm{SD}=.62 ; \mathrm{Mean}_{\text {girls }}=\right.$ $3.10, \mathrm{SD}=.72)$. A very large majority of these same-gender groups (33) were coupled to a mixed-gender group. In one partnership boys communicated with boys; in two partnerships boys communicated with girls.

\section{Context}

As the literature review has revealed, type of CMC matters and should therefore be specified in some detail. Baron 
(2004) suggests making a distinction between types of CMC on the basis of two dimensions, namely: (a) synchronous versus asynchronous, and (b) one-to-one versus one-to-many. In a formal characterization e-mail is asynchronous and one-to-one, but in practice the distinction is not always cut and dried. For example, e-mail in the form of spam is a 'one-to-many' communication. In other words, it is important to describe how CMC is used in practice.

Email use in the present study was asynchronous. Schools used e-mail when it best suited their schedule. This made planning flexible, as partners did not need to monitor their e-mail simultaneously. An added benefit was that there was no pressure to react immediately. Partners could take time to reflect on what they wanted to say before sending a message. A disadvantage of this timing was it did not allow for a swift exchange of questions and answers.

The e-mail exchanges in the study can further be characterized as 'one-to-one'. Even though the children always worked in groups, the communication is best seen as oneto-one because most of the time groups were acting in unison. This can be illustrated with various observations from the study. For example, groups nearly always referred to themselves as a unified group in salutatory parts of the message (e.g., "From the Bike catchers," "Greetings from the Gang"). Likewise, they generally spoke with one voice about design issues and communication (e.g., "we built a boat," "we asked our teacher," "Our name is much nicer than yours," "we think your message was too short"). Even so, groups occasionally discussed a single member ("During construction Liana hit her thumb twice," "we're sorry to hear that Jean is ill"), and now and then members presented themselves separately in the salutations ("Hello Michiel, Roderick, Niek, Nienke and Nur," "Greetings from the Plastic eaters (John, Mark and Elroy"). For within-group influence an important question is whether group composition will strengthen or weaken gender-linked language tendencies. Several empirical studies on CMC have shown that same-sex groups enhance gender-linked language tendencies (e.g., Colley and Todd 2002; Epley and Kruger 2005; Fitzpatrick et al. 1995; Palomares 2004). In other words, we should probably expect that the same-sex grouping of boys and girls contributes to the chances of finding gender-linked language use.

Another important context characteristic is that the communications take place between boys-to-mixed or girlsto-mixed partnerships. For between-group influences a critical question is "What are the chances that the boys or girls accommodate to the communicative styles of their partner?" In face-to-face situations, communicating partners sometimes mimic each other's postures, mannerisms and facial expressions. This often unintentional, non-verbal adaptation is known as the Chameleon effect (Chartrand and Bargh 1999). Several gender studies with adults in face-to-face settings report a similar alignment for language use (e.g., Hanna and Murachver 1999; Thomson et al. 2001). Robertson and Murachver (2003) even found signs of alignment for children between 7 and 12 years old. Should we also expect such alignment in the present study? The answer is 'probably not,' because the communicative context more strongly invites groups to develop and maintain their identity than to adapt to their partner. According to communication accommodation theory (CAT; Giles et al. 1991), an important condition for alignment is 'in-group' or 'out-group' focus. CAT argues that when people are concerned primarily with defining group identity and maintaining group boundaries, they are unlikely to accommodate to their conversational partner and may even accentuate differences. In contrast, when people are mainly concerned with social approval and affiliation, speech alignment with the partner is probable. In our study, groups seemed primarily concerned with their in-group identity. In addition, we found very few signs of alignment in the features of the e-mails that we examined. These moments appeared to be reserved mainly to the salutations, in which we occasionally saw partners copy or adapt an unusual greeting (e.g., "Bye!!!" -> "Bye !!!!!!!"). But here, too, it was far more common for groups to repeat their own, earlier salutation.

\section{Procedure}

Classrooms were invited to take part in a series of lessons in the field of design and technology into which e-mail use was integrated. The lessons revolve around the creation of an object that can clean a pond of plastics, oil, wood and other types of litter. Teachers were acquainted with the setup of the study in a face to face meeting at the University. During this meeting they received a manual that provided detailed support for setting up the six 2-h lessons. The meeting stressed that teachers should aim for a turn-taking pattern in which there would be one e-mail sent and received for each lesson. This advice was based on our experiences in an earlier, comparable study (Van der Meij et al. 2005), in which we found that such an exchange pattern yielded more interactive communications (i.e., more questions and reactions) and also improved the link between questions and responses. The advice also facilitates the difficult point of aligning classroom lesson calendars (Vinagre 2005). Teachers formed partnerships during the meeting, thus connecting classrooms from one school to classrooms from another. This partnership remained intact throughout the project. About 1 week before the start of the project and 1 week after its completion the children filled in an attitude questionnaire.

Lessons had an e-mail moment at the beginning (reception) and end (production). Each lesson began with a discussion of the received e-mails. Production of an 
e-mail at the end was preceded by an individual freewriting exercise and a group discussion. The freewriting exercise (Elbow 1973) begins with a few minutes of silence in which the children reflect about the just-completed lesson. Thereafter, there are five minutes in which the children must try to write down their thoughts as quickly as possible. Next, the children engage in a group discussion in which they talk about what they want to write to their partner. The result is written down on paper, typed as e-mail and sent out.

\section{Materials}

The attitude questionnaire assesses how children perceive the benefits of teamwork (compare Yang and Liu 2005). [The questionnaire does not focus on e-mail use, because most of the children lacked e-mail experience before the start of the project]. For task-orientation we examine the constructs of 'knowledge development' and 'motivation.' For personorientation we look at 'active interaction' and 'socialize.' Each construct is measured with four questions. Each question has two alternatives that signal negative appreciation or low presence and two alternatives that signal positive appreciation or high presence. Answers are given on a four-point Likertscale, with higher scores reflecting a more positive appraisal.

Questions for motivate focus on general relevance of teamwork for academic learning (i.e., Do you find it valuable to work in a small group?). Questions for develop knowledge measure information exchange and knowledge development. They signal an appreciation of teamwork for co-construction of knowledge (i.e., Do you hear new things when you work in a small group?). Questions for socialize measure person-orientation. These questions inquire after social appreciation of working together with other students in a group (i.e., Do you find it cozy to work in a small group?). Questions for active interaction revolve around various possibilities for active participation. The questions measure appreciation of engaging in different types of active exchanges or dialogues during teamwork (i.e., Do you like to express your opinion while working in a small group?). All materials were in Dutch. English translations in this paper were done to make the materials (and all other examples) accessible to the readers.

\section{Coding}

Emails were first segmented into clauses and then coded and scored. Text length was measured with a word count and in units of meaning. A word count is sensitive to preferences in choice of words, phrases and syntax, which makes it highly suitable for detecting differences in elaboration. The unit of meaning gives a sense of the number of ideas presented in a message. It nicely complements the word count measure as a signal of elaboration. The clause was used as the unit of measurement (e.g., "We have continued with our apparatus," "Hello John and Mike," and "We are ready"). Emoticons were rarely used. In contrast, the children frequently employed other visual markers to emphasize words or phrases. We found three types of strengtheners: an excess of letters in a word (e.g., 'veeeerrrryyyy,' 'niiiiice'), an excess of question or exclamation marks, and an unusual presence of capitals. Only expressions with two or more added letters, or stretches of three capitals or punctuation marks were counted as markers to minimize the risk of including spelling errors. For task-oriented talk, a distinction is made between domain talk and communicative talk. Domain talk includes all discussions about the topic of the lessons. In communicative talk the children mainly discuss producing, sending and receiving e-mails. This category also includes greetings. Discussions about hobbies and other personal matters are coded as personal talk.

Coders worked with a codebook. Six coders classified different aspects of the e-mails. A minimum of two coders always scored $10 \%$ of the data jointly to assess reliability. Thereafter, coders independently scored between 25 to $50 \%$ of the data. Reliability for segmentation and coding varied between .79 and .94 (Cohen kappa).

\section{Data Analyses}

The 197 e-mails in the corpus represent a very large percentage of all e-mail communications that took place. In theory we could have received 214 messages (36 groups $\times 6$ lessons, minus two groups in which two lessons were combined into one). In all, these e-mails consisted of 2,402 units of meaning and a total of 15,459 words.

Individual scores on the attitude questionnaire were aggregated into mean scores for groups to relate these to the data for content of communication. Data were analyzed with multivariate analysis of variance, followed by univariate analyses of variance if the first was statistically significant. Gender was treated as a factor. For attitude the two moments of assessment were treated as repeated measures. Only statistically significant differences for dependent variables will be reported. To stay on the conservative side, all tests were bi-directional, with $\alpha$ set at 0.05 . For repeated measures, the partial eta square $\left(\eta_{p}^{2}\right)$ reports effect size. For 5other statistically significant findings Cohen's $d$-statistic is used. Values of $d$ ranging between .20 and .50 are medium effects; higher values are considered large effects (Cohen 1988).

Data-analyses indicated that group size correlated with text length $(r=.47, p<.001)$. Group size was therefore treated as a covariate in the analyses. In calculations of percentages the number of clauses served as the denominator. 


\section{Results}

\section{Attitude Towards Communication}

There were no main gender differences for attitude, but there were two statistically significant effects of time (see Table 3). The children considerably depreciated the taskrelated aspects of teamwork as signaled by a lower evaluation at the end for motivate, $F(1,34)=18.54, p<$ $.001, \eta_{p}^{2}=.35$, as well as develop knowledge $F(1,34)=$ 9.81, $p=.004, \eta_{p}^{2}=.22$.

\section{Succinct Versus Elaborate}

A MANCOVA on all three measures of style signaled the presence of a statistically significant effect of gender, $F$ $(3.31)=2.85, p=.05$. Both measures of text length showed that girls' e-mails were more elaborate than those of boys (see Table 4). The e-mails from girls contained 18\% more words, $F(1,33)=4.89, p=.03, d=.70$, and $15 \%$ more clauses, $F(1,33)=4.28, p=.05, d=.63$. The large effect size comes along with a fairly consistent pattern of girls presenting longer texts. In five of the six rounds of messages girls produced more elaborate e-mails. The gender difference is also not mere verbosity. Girls also wrote e-mails that were richer in content, in that they contained more clauses than the e-mails of boys.

In addition, the e-mails of girls contained more markers than those of boys, $F(1,33)=4.64, p=.04, d=.75$. The large effect size reflects the huge difference in frequency, with girls using strengtheners more than twice as often. Illustrative examples from the e-mails are:

'and you also WRITE things wrong like: maked.' 'And Jael IS a GIRL' 'Greetings Heleen ,Jessica, The Oil searchers bye !!!!!!!!!!!!!!!!!!!!!!!!!!!!!'’ 'What are you making?????' 'because the iron thread was veeeeeeerrrrrrryyyyy weak'
Table 4 Means (standard deviation between parentheses) for boys and girls on the variables for the style dimension succinct-elaborate.

\begin{tabular}{llll}
\hline \multirow{3}{*}{ Succinct-elaborate style } \\
\cline { 2 - 4 } & Words & Clauses & Markers \\
\hline Boys & $71.71(19.31)$ & $11.33(2.70)$ & $4.32(5.27)$ \\
Girls & $84.79(17.69)^{*}$ & $12.99(2.58)^{*}$ & $8.81(6.66)^{*}$ \\
\hline
\end{tabular}

For words and clauses the means are the actual numbers per e-mail. For markers the means are percentages.

$* p<.05$

Task Talk versus Personal Talk

A MANCOVA on the three measures of topic of communication signaled a marginally significant effect of gender, $F(2,32)=2.55, p=.09$. The ANOVA indicated that boys more often discussed communicative issues, $F(1,35)=5.14$, $p=.03, d=.74$ (see Table 5). Apart from the first e-mail, they always dedicated a higher proportion of their talk to issues of communication than did girls. Communicative talk, together with domain talk, has been classified as communication with a task-oriented focus. It includes discussions about writing an e-mail and communicating by e-mail. The finding for communicative talk is in line with the view that boys' talk is more task-oriented. But it is a subtle difference at best, given the marginal multivariate effect, the (nonsignificant) preference of girls to have relatively more discussions about the domain and the absence of a gender difference for discussions on personal matters, $F(1,35)<1$, n.s. In short, the data indicate that the topic of the children's talk is more alike than different.

Two statistically significant within-gender variations were found for the relation between attitude and topic of communication. The one for boys signals the presence of a possibly interesting antecedent; the one for girls points to a possibly interesting consequence. For boys we found negative, statistically significant correlations of .55 and

Table 3 Means (standard deviation between parentheses) for boys and girls on attitude scales.

\begin{tabular}{|c|c|c|c|c|c|c|c|c|}
\hline & \multicolumn{4}{|l|}{ Task scales } & \multicolumn{4}{|c|}{ Person scales } \\
\hline & \multicolumn{2}{|l|}{ Motivate } & \multicolumn{2}{|c|}{ Develop knowledge } & \multicolumn{2}{|l|}{ Socialize } & \multicolumn{2}{|c|}{ Actively interact } \\
\hline & Before & After & Before & After & Before & After & Before & After \\
\hline Boys & $3.22(.25)$ & $2.69(.66)^{*}$ & $2.62(.44)$ & $2.34(.35)^{*}$ & $3.16(.36)$ & $3.02(.41)$ & $2.89(.32)$ & $2.70(.37)$ \\
\hline Girls & $3.21(.41)$ & $2.42(.61)^{*}$ & $2.49(.39)$ & $2.40(.37)^{*}$ & $3.15(.46)$ & $3.12(.50)$ & $2.74(.40)$ & $2.69(.39)$ \\
\hline
\end{tabular}

For each scale the minimum score is 1 - the maximum is 4 ; a higher score reflects more appreciation of purpose. Reliability findings for the scales are (Cronbach's $\alpha ; b$ before, $a$ after). Motivate $\left(\alpha_{\mathrm{b}}=.75 ; \alpha_{\mathrm{a}}=.74\right)$; develop knowledge $\left(\alpha_{\mathrm{b}}=.69 ; \alpha_{\mathrm{a}}=.72\right)$; socialize $\left(\alpha_{\mathrm{b}}=.85 ; \alpha_{\mathrm{a}}=.85\right)$; actively interact $\left(\alpha_{\mathrm{b}}=.68 ; \alpha_{\mathrm{a}}=.73\right)$. Statistical differences signal an effect of time.

$* p<.001$ 
Table 5 Means (standard deviation between parentheses) for boys and girls on topical preferences.

\begin{tabular}{llll}
\hline & Task Talk & & Personal Talk \\
\cline { 2 - 3 } & Domain Talk & Communicative Talk & \\
\hline Boys & $44.47(11.55)$ & $41.06(7.57)^{*}$ & $14.47(10.91)$ \\
Girls & $48.91(13.84)$ & $35.58(7.19)$ & $15.51(10.66)$ \\
\hline
\end{tabular}

Scores are percentages.

$* p<.05$

higher, $p<.04$, between all attitude scales before the start of the project and personal talk. These outcomes indicate that boys who start with relatively high expectations of the benefits of teamwork discuss personal matters less often in their communication. For girls we found positive and statistically significant correlations between their task scales scores at the end and domain talk, $r_{\mathrm{kndev}}=.45, p=.04$, and $r_{\text {motiv }}=.45, p=.04$. These findings indicate that girls who valued teamwork for task-oriented purposes relatively more highly after project completion also had more task talk in their e-mails.

\section{Conclusion}

We found no main gender-linked differences for attitudes toward functional uses of CMC. The absence may be due to how we measured attitude. We assessed the children's appreciation for group work for the whole project rather than just for e-mail, because the children had no experience with e-mail at the start of the project. Also, we did not ask separate questions for within-group and between-group communications even though these differ in critical ways. Within-group communications were always face-to-face with known participants of the same gender. In contrast, between-group communications relied completely on email and involved partners of a mixed-gender group that children could get to know only in the course of the project. In other words, perhaps we measured attitude in ways that were too general for gender-linked differences to emerge.

The significant depreciation of group work for taskrelated purposes suggests that the children started the project with unrealistically high expectations for the relevance of group communications. The scores for knowledge development especially indicate that the children were disappointed about the number of useful ideas contributed by their partners. Later in the conclusion we return to this point, when we discuss how the nature of the e-mail exchange seems best characterized as a co-presentation of knowledge, while a co-construction of knowledge could have fueled more positive sentiments toward knowledge development.
The predominant use of an elaborate style by girls may reflect a difference in language proficiency. Girls from elementary school age can generally call upon a greater repertoire of language choices than boys. That this capacity difference allows them to produce e-mails with more words is self-evident. And perhaps a greater linguistic fluency helped girls to produce more ideas (i.e., clauses) in their emails. Artful language use may also account for the finding that girls embellish their texts with more strengtheners. For example, an expression such as 'veeeerrrry' conveys a deliberate misspelling. An excess of question marks and exclamation marks (Greetings !!!!!????) or an uncommon use of capitals (e.g., DO THAT) can likewise signal skill in handling interpunction. A difference in language skill can thus have played a major role in the finding that girls used a verbally and visually more elaborate style. The literature review provides additional accounts. Baron (2004) suggests that there is a difference in adherence to normative language and, more generally, a more social orientation of females. Other authors (e.g., Witmer and Katzman 1997; Wolf 2000) mention differences in relational, aesthetic and emotional expressiveness. In short, the female preference for markers found in this study may stem from gender-linked differences in language skills as well as various motifs.

The findings for content have been very reassuring for those teachers in the study who initially feared that students would be using e-mail mainly to chat. Boys' and girls' topical preferences were similar rather than different. In addition, all groups were sufficiently motivated to stay taskfocused in their communication. We believe that the functional embedding of CMC in classroom practices played an important role in this outcome. The happy combination of task and medium use in the setting helped trigger taskfocused behaviors for boys and girls alike. The main tenet of functional embedding is to aim for interdependence of task (function) and medium choice within context. This goes one step further than Walther et al. (2005a) call for unpacking various functional activities of Internet use.

The literature review and ensuing empirical study raise several questions for further research on gender-linked differences in CMC in an educational setting: (1) What issues of audience, task and context are likely to affect gender-linked behaviors? (2) What are the antecedents and consequences of any differences?

A critical issue in addressing the first question is how $\mathrm{CMC}$ is embedded in classroom practices. Is it an add-on or functionally integrated component? And if functionally integrated, which functions does it support? In O'Dowd's (2003) study, e-mail played a pivotal role in the student's second-language learning. This explains why discussion topics were prescribed, why teachers regularly gave feedback and why communications were judged to be a success or failure. In our study, e-mail added meaning to the task of 
reflecting on classroom experiences and it allowed the children to share their experiences with others. Content was left free and teacher interference minimal. In this context, qualifying the e-mail communications in terms of (task) successes or failures seems odd or even inappropriate. The children did not need the interactions to complete their main task; communicative failures did not seriously hamper project completions. Our impression was that children used e-mail mainly to present their own accounts of task-related processes and outcomes. Framed differently, e-mail served to co-present knowledge; moments of co-construction of knowledge were scarce. For the present study this observation remains speculative, because we did not examine this aspect of the communication. However, in other studies with a comparable set-up we did find evidence of a predominant co-presentation (De Vries 2004; Van der Meij et al. 2005). These studies also revolved around elementary school children's use of e-mail for communication about a design task. Children predominantly used e-mail to tell the partner what they were doing and thinking in their own project. Helpful suggestions for the partner and moments of joint knowledge creation were rare. The finding may have been a consequence of how the turn-taking pattern was organized. Just as in the present study, groups sent each other an e-mail once after every lesson. This practice invariably yielded a considerable response delay and thereby practically obstructed the use of e-mail for getting a swift response on pressing issues. In other words, while the exchange pattern optimized e-mail use for reflection and community building, it could, at the same time, have reduced its potential for joint knowledge construction and the emergence of a gender-linked difference therein.

With regard to the second question, we note that the empirical study was specifically designed to yield some information on antecedents and consequences of communicative behaviors by measuring the children's attitudes at the start and end of the project. This is unusual in a study that mainly depends on a corpus-based analysis of language use. It is far more common to infer antecedents from observed language patterns (e.g., Mulac 1998) or to engage in experimentation to examine the impact, consequences, of key input factors.

In the present study, communicative failures had little effect on the children's school work. In other situations there may be important consequences for task completion and learning. Researchers, often stimulated by the finding that boys underachieve in school, therefore call for attention to finding ways in which boys especially can improve their communication (e.g., Younger et al. 2005). In line with this view, Savicki et al. (2002) have tried to teach boys some of the strategies that girls of the same age already successfully employ. Another option would be to find ways to improve the strategies that boys commonly employ. Either choice should, in our view, be firmly rooted in the communications that boys and girls spontaneously employ. This study has provided some insights into aspects of such communication.

More generally, systematic examinations of genderlinked differences in language use in relation to their antecedents and consequences seem called for. Such research efforts preferably are based on a uniform theoretical framework - an illuminating account of theories from which such studies could start is advanced by Walther and Parks (2002) - are long-term, and switch between experimentation and naturalistic observations.

\section{References}

Adrianson, L. (2001). Gender and computer-mediated communication: Group processes in problem solving. Computers in Human Behavior, 17, 71-94.

Allen, B. J. (1995). Gender and computer-mediated-communication. Sex Roles, 32, 557-563.

Arnot, M. (2006). Freedom's children: A gender perspective on the education of the learner-citizen. International Review of Education, 52, 67-87.

Baron, N. S. (2002). Who sets e-mail style? Prescriptivism, coping strategies, and democratizing communication access. The Information Society, 18, 403-413.

Baron, N. S. (2004). See you online. Gender issues in college student use of instant messaging. Journal of Language and Social Psychology, 23, 397-423.

Boneva, B., Kraut, R., \& Frohlich, D. (2001). Using e-mail for personal relationships. The difference gender makes. American Behavioral Scientist, 45, 530-549.

Chartrand, T. L., \& Bargh, J. A. (1999). The chameleon effect: The perception-behavior link and social interaction. Journal of Personality and Social Psychology, 76(6), 893-910.

Cohen, J. (1988). Statistical power analysis for the behavioral sciences (2nd ed.). Hillsdale, NJ: Lawrence Erlbaum Associates.

Colley, A. (2003). Gender differences in adolescents' perceptions of the best and worst aspect of computing at school. Computers in Human Behavior, 19, 673-682.

Colley, A., \& Todd, Z. (2002). Gender-linked differences in the style and content of e-mails to friends. Journal of Language and Social Psychology, 21, 380-392.

Colley, A., Todd, Z., Bland, M., Holmes, M., Khanom, N., \& Pike, H. (2004). Style and content in e-mails and letters to male and female friends. Journal of Language and Social Psychology, 23, 369-378.

Crystal, D. (2001). Language and the internet. Cambridge: Cambridge University Press.

Danet, B. (1998). Text as mask: Gender and identity on the Internet. In S. Jones (Ed.), Cybersociety 2.0 (pp. 129-158). Thousand Oaks, CA: Sage.

De Vries, B. (2004). Opportunities for reflection: Email and the web in the primary classroom. $\mathrm{PhD}$ Thesis. University of Twente, Enschede, the Netherlands. Retrieved March 25, 2006 from http://purl.org/utwente/48235.

Dolle-Willemsen, T. E. (1997). Gezien onderscheid naar sekse in het basisonderwijs. Interactie als invalshoek. [Considering gender differences in elementary school. The perspective of interaction.] Tilburg: Tilburg University Press.

Elbow, P. (1973). Writing without teachers. New York: Oxford University Press. 
Epley, N., \& Kruger, J. (2005). When what you type isn't what they read: The perseverance of stereotypes and expectancies over email. Journal of Experimental Social Psychology, 41, 414-422.

Fitzpatrick, M. A., Mulac, A., \& Dindia, K. (1995). Gender-preferential language use in spouse and stranger interaction. Journal of Language and Social Psychology, 14, 18-39.

Frank, B., Kehler, M., Lovell, T., \& Davison, K. (2003). A tangle of trouble: Boys, masculinity and schooling-future directions. Educational Review, 55, 119-133.

Giles, H., Coupland, N., \& Coupland, J. (1991). Accommodation theory: Communication context, and consequence. In H. Giles, J. Coupland, \& N. Coupland (Eds.), Contexts of accommodation: Developments in applied sociolinguistics (pp. 1-68). New York: Cambridge University Press.

Guiller, J., \& Durndell, A. (2007). Students' linguistic behaviour in online discussion groups: Does gender matter? Computers in Human Behavior, 23, 2240-2255.

Hanna, A., \& Murachver, T. (1999). Gender and conversational style as predictors of conversational behavior. Journal of Language and Social Psychology, 18, 153-174.

Herring, S. C. (1996). Two variants of an electronic message system. In S. C. Herring (Ed.), Computer-mediated communication. Linguistic, social and cross-cultural perspectives (pp. 81-106). Amsterdam: John Benjamins Publishing Company.

Huffaker, D. A., \& Calvert, S. L. (2005). Gender, identity, and language use in teenage blogs. Journal of Computer-Mediated Communication, 10(2). Retrieved October, 3, 2006 from http:// jcmc.indiana.edu/vol10/issue2/huffaker.html.

Itakura, H. (2004). Changing cultural stereotypes through e-mail assisted foreign language learning. System, 32, 37-51.

Jackson, C. (2002). 'Laddishness' as a self-worth protection strategy. Gender and Education, 14, 37-51.

Jaffe, J. M., Lee, Y.-E., Huang, L.-N., \& Oshagan, H. (1999). Gender identification, interdependence, and pseudonyms in CMC: Language patterns in an electronic conference. The Information Society, 15, 221-234.

Jessup, L. M., Connolly, T., \& Tansik, D. D. (1990). Toward a theory of automated group work: The deindividuating effects of anonymity. Small Group Research, 21, 333-348.

Koch, S. C., Mueller, B., Kruse, L., \& Zumbach, J. (2005). Constructing gender in chat groups. Sex Roles, 52, 29-41.

Lee, E. J. (2003). Effects of gendered-character representation on person perception and informational social influence in computer-mediated communication. Computers in Human Behavior, 20, 779-799.

Li, Q. (2002). Gender and computer-mediated communication: An exploration of elementary student's mathematics and science learning. Journal of Computers in Mathematics and Science Teaching, 21, 341-359.

Liaw, M.-L., \& Johnson, R. J. (2001). Email writing as a cross-cultural experience. System, 29, 235-251.

Lindsey, A. E., \& Zakahi, W. R. (1998). Perceptions of men and women departing from conversational sex role stereotypes during initial interaction. In D. J. Canary \& K. Dindia (Eds.), Sex differences and similarities in communication: Critical essays and empirical investigations of sex and gender in interaction (pp. 393-412). Mahwah, NJ: Erlbaum.

Madell, D., \& Muncer, S. (2004). Gender differences in the use of Internet by English secondary school children. Social Psychology of Education, 7, 229-251.

Meelissen, M., \& Drent, M. (2007). Gender differences in computer attitudes: Does the school matter? Computers in Human Behavior. Retrieved May 12, 2007 from http://www.sciencedirect.com/ science/journal/07475632.

Mulac, A. (1998). The gender-linked language effect: Do language differences really make a difference? In D. J. Canary \& K. Dindia
(Eds.), Sex differences and similarities in communication: Critical essays and empirical investigations of sex and gender in interaction (pp. 127-155). Mahwah, NJ: Erlbaum.

Mulac, A., Bradac, J. J., \& Gibbons, P. (2001a). Empirical support for the gender-as-culture hypothesis. Human Communication Research, 27, 121-152.

Mulac, A., Flanagin, A. J., Tiyaamornwong, V., \& Palomares, N. A. (2001b). Gender-linked language differences in virtual group deliberations. Paper presented at the Annual Meeting of the National Communication Association, November.

Mullis, I. V. S., Martin, M. O., Gonzalez, E. J., \& Kennedy, A. M. (2001). PIRLS 2001 international report. Chestnut Hill, MA: International Study Center

O'Dowd, R. (2003). Understanding the other side: Intercultural learning in a Spanish-English e-mail exchange. Language Learning \& Technology, 7(2), 118-144.

O’Neill, R., \& Colley, A. (2006). Gender and status effects in student e-mails to staff. Journal of Computer Assisted Learning, 22, 360-367.

Odell, P. M., Korgen, K. O., Schumacher, P., \& Delucchi, M. (2000). Internet use among female and male college students. CyberPsychology \& Behavior, 3, 855-862.

Oosterwegel, A., Littleton, K., \& Light, P. (2004). Understanding computer-related attitudes through an ideographic analysis of gender- and self-representations. Learning and Instruction, 14, 215-233.

Palomares, N. A. (2004). Gender schematicity, gender identity salience, and gender-linked language use. Human Communication Research, 30, 556-588.

Postmes, T., Spears, R., \& Lea, M. (2000). The formation of group norms in computer-mediated communication. Human Communication Research, 26, 341-371.

Price, L. (2006). Gender differences and similarities in online courses: Challenging stereotypical views of women. Journal of Computer Assisted Learning, 22, 349-359.

Prinsen, F. R., Volman, M. L. L., \& Terwel, J. (2007a). Gender-related differences in computer-mediated communication and computersupported collaborative learning. Journal of Computer Assisted Learning (in press). Retrieved May 12, 2007 from http://www. blackwell-synergy.com/doi/abs/10.1111/j.1365-2729.2007. 00224.x.

Prinsen, F. R., Volman, M. L. L., \& Terwel, J. (2007b). The influence of learner characteristics on degree and type of participation in a CSCL environment. British Journal of Educational Technology (in press). Retrieved May 12, 2007 from http://www.blackwellsynergy.com/doi/full/10.1111/j.1467-8535.2006.00692.x.

Reay, R. (2001). 'Spice girls', 'Nice girls', 'Girlies', and 'Tomboys': Gender discourse, girls' cultures and femininities in the primary classroom. Gender and Education, 13, 153-166.

Robertson, K., \& Murachver, T. (2003). Children's speech accommodation to gendered language styles. Journal of Language and Social Psychology, 22, 321-333.

Sanders, J. (2005). Gender and technology in education: A research review. Seattle: Center for Gender Equity. Bibliography retrieved March 20, 2006 from http://www.umbc.edu/ cwit/pdf/gendertechbib rev1.pdf.

Savicki, V., Kelley, M., \& Ammon, B. (2002). Effects of training on computer -mediated communication in single or mixed gender small task groups. Computers in Human Behavior, 18, 257-269.

Savicki, V., Kelley, M., \& Lingenfelter, D. (1996). Gender, group composition, and task type in small task groups using computermediated communication. Computers in Human Behavior, 12, $549-565$.

Sussman, N. M., \& Tyson, D. H. (2000). Sex and power: Gender differences in computer-mediated interactions. Computers in Human Behavior, 16, 381-394 
Tannen, D. (1994). Gender and discourse. New York: Oxford University Press.

Thomson, R., \& Murachver, T. (2001). Predicting gender from electronic discourse. British Journal of Social Psychology, 40, 193-208.

Thomson, R., Murachver, T., \& Green, J. (2001). Where is the gender in gendered language? Psychological Science, 12, 171-175.

Van der Meij, H., De Vries, B., Pieters, J. M., Boersma, K. Th., \& Wegerif, R. (2005). An examination of interactional coherence in email use in elementary school. Computers in Human Behavior, 21, 417-439.

Van Langen, A., \& Driessen, G. (2006). Sekseverschillen in onderwijsloopbaan. Een internationaal comparatieve studie. [Gender differences in educational carriers. An international comparative study]. Nijmegen, the Netherlands: ITS.

Vinagre, M. (2005). Fostering language learning via email: An English-Spanish exchange. Computer Assisted Language Learning, 18, 369-388.

Walther, J. B., Gay, G., \& Hancock, J. T. (2005a). How do communication and technology researchers study the Internet? Journal of Communication, 55, 632-657.

Walther, J. B., Loh, T., \& Granka, L. (2005b). Let me count the ways. The interchange of verbal and nonverbal cues in computer mediated and face-to-face affinity. Journal of Language and Social Psychology, 24, 36-65.

Walther, J. B., \& Parks, M. R. (2002). Cues filtered out, cues filtered in. Computer Mediated Communication and relationships. In M. L. Knapp \& J. A. Daly (Eds.), Handbook of interpersonal communication (3rd ed., pp. 529-563). Thousand Oaks, CA: Sage.

Witmer, D. F., \& Katzman, S. L. (1997). On-line smiles: Does gender make a difference in the use of graphic accents? Journal of Computer Mediated Communication, 2. Retrieved April 27, 2006 from http://jcmc.indiana.edu/vol2/issue4/witmer1.html.

Wolf, A. (2000). Emotional expression online: Gender differences in emoticon use. CyberPsychology \& Behavior, 3, 827-833.

Yang, S. C., \& Liu, S. F. (2005). The study of interactions and attitudes of third-grade students' learning information technology via a cooperative approach. Computers in Human Behavior, 21, $45-72$.

Yates, S. J. (2001). Gender, language and CMC for education. Learning and Instruction, 11, 21-34.

Younger, M., Warrington, M., Gray, J., Rudduck, J., McLellan, R., Bearne, E., et al. (2005). Raising boys' achievement. Research Report No 636. Faculty of Education, University of Cambridge, UK. 